OPEN ACCESS ISSN 2548-2246 (online) ISSN 2442-9139 (print)

Edited by:

Paramitha Amelia Kusumawardhani Reviewed by: Suyani

*Correspondence: Dewi Taurisiawati Rahayu deetaurisia@gmail.com

Received: 24 Desember 2019

Accepted: 05 Januari 2020 Published: 05 April 2020

Citation:

Rahayu DT and A (2020)

Pendampingan Kader dengan Kunjungan Antenatal Care (Anc) Ibu Hamil Risiko Tinggi Di Puskesmas Jelakombo Jombang.

Midwiferia Jurnal Kebidanan. 6:2. doi: 10.21070/midwiferia.v\%vi\%i.42
Pendampingan Kader dengan Kunjungan Antenatal Care (Anc) lbu Hamil Risiko Tinggi Di Puskesmas Jelakombo Jombang

\section{Private community assistance in antenatal care at high risk pregnant women in Public Health Center of Jelakombo Jombang}

\author{
Dewi Taurisiawati Rahayu*, Askabulaikhah \\ STIKES Karya Husada Kediri, JI Soekarno Hatta No. 07, Bendo, Pare-Kediri, 64225, Indonesia
}

Maternal Mortality Rate (MMR) in 2012 was 359 per 100,000 live births. In 2015, based on 2015 SUPAS data, both MMR and IMR showed a decrease (MMR 305 / 100,000 $\mathrm{KH}$; IMR 22.23 / $1000 \mathrm{KH}$ ). The purpose of this study was to determine the effect of the implementation of cadre assistance on antenatal care (ANC) visits of high-risk pregnant women in Jelakombo Jombang. This type of research is correlational with the Cross Sectional approach. Population 63 high risk pregnant women, sample 54 high risk pregnant women. The study was conducted from 03 to 17 July 2019. The independent variable was the implementation of cadre mentoring and the dependent variable was the ANC visit. The side technique used is simple random sampling. Data obtained from ANC questionnaire and $\mathrm{MCH}$ Book Checklist. Data analysis using the Chi square test. The results of the implementation of cadre mentoring were quite good as many as 32 respondents (59.3\%). ANC visits were mostly active in visiting ANC, namely 40 respondents (74.1\%). Implementation of pregnant women by good cadres 32 respondents, most respondents 32 high risk mothers (93.8\%) actively visited ANC. Statistical test results using the chi square test obtained $r=0,001(r<0,05)$ so that Ho was rejected means that it was concluded there was a correlation between the Implementation of Cadre Assistance with ANC Visit of Risti Pregnant Women at Jelakombo Health Center in Jombang Regency.

Keywords: Assistance, ANC, high-risk pregnant women

Angka Kematian Ibu (AKI) pada tahun 2012 sebesar 359 per seratus ribu kelahiran hidup. Berdasarakan data yang bersumber dari SUPAS pada tahun 2015 baik kematian ibu maupun kematian bayi kelahiran; AKB 22,23 per seribu kelahiran). Tujuan penelitian ini adalah untuk mengetahui hubungan pelaksanaan pendampingan kader terhadap kunjungan antenatal care (ANC) ibu hamil resiko tinggi di puskesmas Jelakombo Jombang.

Jenis penelitian ini korelasional dengan pendekatan Cross Sectional. Populasi 63 ibu hamil risiko tinggi, sampel 54 ibu hamil risiko tinggi. Penelitian dilakukan pada tanggal 03 s/d 30 Juli 2019. Teknik samping yang digunakan adalah simple random sampling. 
Data diperoleh dari kuesioner, Checklistdan Buku KIA. Analisa data menggunakan uji Chi square.

Hasil penelitian pelaksanaan pendampingan kader cukup baik sebanyak 32 responden (59,3\%). Kunjungan ANC sebagian besar aktif melakukan kunjungan ANC yaitu 40 responden $(74,1 \%)$. Pelaksaaan ibu hamil oleh kader yang baik 32 responden, sebagian besar responden 32 ibu risiko tinggi (93,8\%) aktif melakukan kunjungan ANC. Hasil uji statistik dengan menggunakan uji Mann-Whitney $U$ didapat $r=0,001(r<0,05)$ sehingga $\mathrm{H}_{o}$ ditolak berarti disimpulkan ada hubungan Pelaksanaan Pendampingan Kader dengan Kunjungan ANC Ibu Hamil Risti di Puskesmas Jelakombo Kabupaten Jombang.

Keywords: Pendampingan, ANC, ibu hamil resiko tinggi.

\section{PENDAHULUAN}

Pada awal tahun 2010 kematian ibu di seluruh dunia mencapai sekitar 287.000 dan mengalami peningkatan hingga mencapai angka 303.000 di tahun 2015 (Liu et al. (2015) ). Evidence based menjadi dasar berbagai inovasi intervensi upaya penurunan angka kesakitan maupun kematian ibu. Meskipun berbagai usaha sudah dilaksanakan untuk mengurangi kematian ibu, namun masih sekitar 800 ibu meninggal setiap harinnya disebabkan oleh komplikasi pada kehamilan dan persalinan (Liu et al. (2015) ). Total angka kematian neonatal juga cukup tinggi, meskipun ketersediaan intervensi berbasis bukti dapat mencegah hingga $72 \%$ dari kematian neonatal (Hicks dkk., 2013). Angka Kematian Ibu (AKI) dan Angka Kematian Bayi (AKB) merupakan salah satu indikator pembangunan kesehatan dalam RPJMN 2015-2019 dan SDGs. Menurut data SDKI, Angka Kematian Ibu sudah mengalami penurunan pada periode tahun 1994-2012 yaitu pada tahun 1994 sebesar 390 per 100.000 kelahiran hidup, tahun 1997 sebesar 334 per 100.000 kelahiran hidup, tahun 2002 sebesar 307 per 100.000 kelahiran hidup, tahun 2007 sebesar 228 per 100.000 kelahiran hidup namun pada tahun 2012, angka Kematian Ibu meningkat kembali menjadi sebesar 359 per 100.000 kelahiran hidup. Untuk AKB dapat dikatakan penurunan on the track (terus menurun) dan pada SDKI 2012 menunjukan angka 32/1.000 KH (SDKI 2012). Dan pada tahun 2015, berdasarkan data SUPAS 2015 baik AKI maupun AKB menunjukkan penurunan (AKI 305/ $100.000 \mathrm{KH}$; AKB 22,23/ $1000 \mathrm{KH}$ ) (Gunawan et al. (2016) ). Kematian ibu disebabkan oleh multi faktor diantaranya berasal dari kondisi kesehatan ibu sendiri dan riwayat kesehatan keluarga ibu, sumber daya kesehatan, sarana dan prasaran pelayanan kesehatan, faktor sosio-kultural masyarakat, ekonomi, dan tingkat pendidikan ibu. Faktor budaya masyarakat memiliki pengaruh yang cukup besar, oleh karena itu perlu adanya upaya meningkatkan peran serta masyarakat untuk turut serta dalam menurunkan jumlah kematian Ibu. (Jombang (2017)). Adakalanya budaya yang dipercaya terkait kehamilan, persalinan, perawatan nifas dan neontal bisa merugikan ibu dan bayinya. Masih banyak berbagai mitos tentang pantang makan yang tentunya mengganggu pemenuhan nutrisi ibu dan bayinya ( $R$ (2013) ). Propinsi Jawa Timur mempunyai inovasi program yang telah dilaksanakan sejak tahun 2013 yaitu Gerakan Bersama Amankan Kehamilan (GEBRAK) dan pendampingan ibu hamil resiko tinggi oleh kader kesehatan. Pendampingan ini dilaksanakan mulai dari awal kehamilan sampai ibu melewati masa nifasnya. Provinsi Jawa Timur menjadi pionir dalam melaksanakan program pendampingan ibu hamil. (Timur (2014)). Petugas atau kader kesehatan yang akan mendampingi ibu hamil terlebih dulu harus mengikuti pelatihan untuk membekali kader dengan pengetahuan dan ketrampilan dalam mendampingi ibu. Bidan desa bisa memantau secara intensif kondisi kesehatan ibu hamil yang beresiko tinggi dari proses pendampingan tersebut. Kader akan lebih cepat dalam memberikan informasi ke bidan.

Provinsi Jawa Timur menggunakan kartu skor Puji Rohyati (KSPR) sebagai instrumen untuk melakukan skrining resiko pada ibu hamil. Sesuai dengan jumlah skornya ibu hamil dikategorikan ke resiko rendah, tinggi dan sangat tinggi. Setiap ibu hamil memamg beresiko namun ibu hamil yang beresiko tinggi secara skor lebih menjadi prioritas dalam program ini.

Kecamatan Jombang yang terletak di Kabupaten Jombang, menjadi salah satu kecamatan penyumbang kematian ibu di kabupaten Jombang, pada tahun 2017 ada 4 kematian ibu. Penye- 
bab kematian ibu tersebut maasih sama seperti tahun-tahun sebelumnya yaitu PEB dan HPP. Kegiatan pendampingan ibu hamil resiko tinggi oleh kader Posyandu dilaksanakan sebagai salah satu upaya untuk memberdayakan masyarakat berperan dalam menurunkan jumlah kematian Ibu. Bentuk peran serta masyarakat dalam bidang kesehatan ibu dan bayi diantaranya dengan partisipasi anggota masyarakat sebagai kader (Maryati (2017) ). Peran kader dalam program kesehatan Ibu dan Anak adalah untuk menginformasikan segala perasalahan kesehatan yang berhubungan dengan kesehatan ibu hamil, bayi baru lahir serta mampu menjadi penggerak bagi kelompok atau organisasi masyarakat yang ada. Salah satu fungsi kader dalam kesehatan ibu dan anak adalah membantu memotivasi ibu hamil untuk melakukan pemeriksaan kehamilan di tenaga kesehatan.

Dengan adanya pendampingan oleh kader secara tidak langsung membuat keluarga ibu hamil menjadi lebih perduli dan lebih memperhatikan kondisi kesehatan ibu dan bayinya. (Manuaba (2005)).

\section{METODE}

Jenis penelitian ini adalah korelasional dengan pendekatan Cross Sectional. Responden pada penelitian ini berjumlah $54 \mathrm{ibu}$ hamil resiko tinggi skor KSPR $\geq 10$ pada usia kehamilan trimester 2. Instrumen yang digunakan adalah kuesioner, Checklist dan Buku KIA. Penelitian dilaksanakan mulai tanggal 03 Juli s/d 30 Juli 2019 di Puskesmas Jelakombo. Data dianalisa dengan distribusi frekuensi, dan analisa bivariate menggunakan uji Chi square.

\section{HASIL PENELITIAN}

\section{Data Umum}

TABLE 1 | Distribusi usia responden

\begin{tabular}{llll}
\hline No & Usia & Frekuensi & Presentase \% \\
1 & $\leq 16$ tahun & 4 & 7,4 \\
2 & $17-35$ tahun & 41 & 75,9 \\
3 & $>35$ tahun & 9 & 16,7 \\
& Jumlah & 54 & 100 \\
\hline
\end{tabular}

Tabel 1 Distribusi karakteristik responden berdasarkan usia sebagian besar responden 41 responden (75,9\%) berusia 17-35 tahun.

\begin{tabular}{clll} 
TABLE 2 | & Distribusi pekerjaan responden \\
\hline No & Pekerjaan & Frekuensi & Presentase \% \\
1 & lbu rumah tangga & 25 & 46,3 \\
2 & Wiraswasta & 13 & 24,1 \\
3 & Pegawai Swasta & 12 & 22,2 \\
4 & Pegawai Negeri & 2 & 3,7 \\
5 & Buruh/Tani & 2 & 3,7 \\
& Jumlah & 54 & 100 \\
\hline
\end{tabular}

Tabel 2 Distribusi karakteristik responden berdasarakan pekerjaan setengah dari responden 25 responden (46,3\%) adalah ibu rumah tangga.

TABLE 3

\begin{tabular}{llll}
\multicolumn{2}{l}{ Distribusi status gravida } \\
\hline No & Status Kehamilan & Frekuensi & Presentase \% \\
1 & Hamil ke-1 & 22 & 40,7 \\
2 & Hamil ke-2 & 24 & 44,4 \\
3 & Hamil ke-3 & 5 & 9,3 \\
4 & Hamil lebih dari 3 & 3 & 5,6 \\
Jumlah & & 54 & 100 \\
\hline
\end{tabular}

Tabel 3 Distribusi karakteristik responden berdasarkan status gravida adalah hampir setengah dari responden yaitu 24 responden $(44,4 \%)$ termasuk dalam kategori hamil ke-2. 


\section{Data Khusus}

TABLE 4 | Distribusi Kunjugan ANC Ibu Hamil Risti

\begin{tabular}{llll}
\hline No & Kunjungan ANC & frekuensi & $\begin{array}{l}\text { Presentase } \\
\%\end{array}$ \\
1 & Tidak Aktif & 14 & 25,9 \\
2 & & 40 & 74,1 \\
& & 54 & 100 \\
\hline
\end{tabular}

Tabel 4 Distribusi karakteristik responden mengenai kunjungan ANC ibu hamil risti adalah sebagian besar responden aktif melakukan kunjungan ANC yaitu 40 responden $(74,1 \%)$.

TABLE 5 | Tabulasi Silang Pelaksanaan Pendampingan Kader dengan Kunjungan ANC Ibu Hamil Risti

\begin{tabular}{llllllll}
\hline \multicolumn{4}{c}{ No } & \multicolumn{3}{l}{ Pelaksanaan Kunjungan ANC } & \multicolumn{3}{l}{ Total } \\
& $\begin{array}{l}\text { Pen- } \\
\text { dampin- }\end{array}$ & $\begin{array}{l}\text { Tidak } \\
\text { gan }\end{array}$ & Aktif & Aktif & & & \\
& Kader & N & $\%$ & N & $\%$ & N & $\%$ \\
1 & Kurang & 0 & 0 & 0 & 0 & 0 & 0 \\
2 & Cukup & 12 & 22,2 & 10 & 18,5 & 22 & 40,7 \\
3 & Baik & 2 & 3,7 & 30 & 55,6 & 32 & 59,3 \\
& Jumlah & 14 & 25,9 & 40 & 74,1 & 54 & 100 \\
\hline
\end{tabular}

Berdasarkan tabulasi silangTabel 5 diketahui bahwa pelaksaaan pendampingan kader pada ibu hamil dalam kategori baik dan termasuk dalam kategori kunjungan ANC yang aktif sebanyak 30 responden (55,6\%). Berdasarkan hasil uji statistik dengan menggunakan uji Chi surae didapat $\mathrm{r}_{\text {value }}=0,001(\mathrm{r}<0,05)$ sehingga $\mathrm{H}_{o}$ ditolak berarti disimpulkan ada hubungan Pelaksanaan Pendampingan Kader dengan Kunjungan ANC Ibu Hamil Risti di Puskesmas Jelakombo Kabupaten Jombang.

\section{PEMBAHASAN}

Pelaksanaan Pendampingan Ibu Hamil Risti oleh Kader Hasil penelitian sebagaimana bisa dilihat di tabel 4 menunjukkan bahwa sebagian besar responden menyatakan didampingi kader cukup baik yaitu 32 responden (59,3\%). Pendampingan oleh kader merupakan salah satu program kesehatan yang di laksanakan untuk memantau ibu hamil terutama yang termasuk dalam kategori resiko tinggi agar bisa dicegah dari kejadian kesakitan dan kematian. Upaya ini dilakukan untuk menurunkan angka kematian ibu dan bayi.

Dari hasil jawaban kuesioner yang telah disebarkan sebagian besar responden mendapatkan pendampingan kader yang baik, yang ditunjukkan rata-rata hasil kuesioner pendampingan kader . Masing - masing memiliki tanggapan 90,29\%, 87,04\%, 81,48\% dan 69,44\% (tanggapan yang rendah). Kader pendamping sebagai motivator menunjukkan tanggapan yang baik dengan (pernyataan no.1 dan no.3) memperoleh prosentase 92,13 dan 89,35\%. Peran kader sebagai mediator juga mendapat tanggapan yang cukup baik dari ibu hamil risti (pernyataan no.7) dengan prosentase $52,78 \%$, dan pernyataan no. 12 mendapatkan tanggapan yang baik (76,85\%). Sementara kader sebagai pendamping ibu hamil risti (pernyataan no. 5, 6, dan 11) mendapat tanggapan yangbaik dengan rentang nilai 78,7\% - 87,04\%.

Hasil ini menggambarkan bahwa pelaksanaan pendampingan ibu hamil risti oleh kader di wilayah kerja puskesmas Jelakombo dapat berjalan dengan baik dan senantiasa perlu ditingkatkan pelayanannya agar upaya pemerintah propinsi Jawa Timur untuk mewujudkan Gerakan Bersama Amankan Kehamilan (GEBRAK) dapat terwujud dengan baik dan dapat melayani ibu hamil secara optimal. Dengan demikian sangat penting melakukan pendampingan bagi ibu hamil khususnya ibu hamil risti dalam upaya memperoleh informasi, motivasi dan dukungan dalam proses kehamilan sampai persalinan. Semakin baik pendampingan yang dilakukan oleh kader, maka semakin meningkat derajat kesehatan ibu hamil risti.

Hal ini sangat menunjang harapan pemerintah, untuk melakukan pendampingan yang dilakukan kader terpilih pada ibu hamil sejak awal kehamilan sampai dengan 40 hari sete- 
lah melahirkan. Selama ibu hamil kader melaksanakan pendampingan dengan cara memantau keadaaan ibu dan memotivasi untuk memeriksakan kehamilan secara rutin dan melahirkan di pelayanan kesehatan yang sesuai dengan resiko kehamilannya. Ibu hamil yang selalu memeriksakan secara rutin akan terdeteksi lebih awal jika ada komplikasi kehamilan dan dapat segera dapat dilakukan penatalaksanaan komplikasi kehamilan.

\section{Kunjungan Antenatal Care Ibu Hamil Risti di Puskesmas Jelakombo}

Hasil penelitian menunjukkan bahwa dari 54 responden sebagian besar 40 responden $(74,1 \%)$ yang aktif melakukan kunjungan ANC dan sebagian kecil dari responden 14 responden (25,9\%)yang tidak aktif. Standar kunjungan ibu hamil yaitu 1 kali pada trimester I, 1 kali pada trimester IIdan 2 kali pada trimester III. Pada kondisi tertentu ibu hamil harus lebih sering memeriksakan kehamilannya.

Dari lembar checlist didapatkan ibu hamil yang memeriksakan kehamilan pada trimester I sebanyak 51 responden dan yang tidak periksa sebanyak 1 responden. Dan 14 orang tidak melakukan pemeriksaan pada trimester III. Pada trimester III responden ada 14 responden yang tidak aktif dalam memeriksakan kehamilannya untuk kunjungan kedua. Dari hasil penelitian dapat diketahui bahwa ibu yang memeriksakan kehamilannya secara aktif jumlahnya lebih banyak dibanding dengan ibu yang tidak aktif memeriksakan kehamilannya.

Antenatal Care (ANC) adalah asuhan kehamilan yang diberikan oleh tenaga kesehatan pada ibu hamil. Pelayanan kesehatan pada kehamilan atau antenatal care mempunyai fokus utama untuk mencegah terjadinya komplikasi obstetri dan untuk melaksanakan deteksi dini kondisi komplikasi, sehingga ibu dan janinnya bisa sesegera mungkin mendapatkan pertolongan. Menurut peneliti, ada 14 ibu risti yang tidak aktif melakukan kunjungan ANC dikarenakan ketidaktahuan bahwa dirinya hamil dalam kondisi yang berisiko tinggi yang memerlukan pengawasan intensif serta adanya faktor lain seperti faktor tingkat perekonomian keluarga. Sebanyak 7 orang responden menyampaikan tidak mempunyai biaya untuk memeriksakan kehamilannya secara mandiri karena tidak mempunyai kartu kepesertaan jaminan kesehatan. Sebanyak 5 orang responden yang lain menyampaikan bahwa mereka jarang memeriksakan kehamilannya karena terkendala tidak adanya anggota keluarga yang mengantar. Sisanya karena ibu hamil tersebut tinggal di luar kota.

Responden yang aktif melakukan.kunjungan ANC maupun yang tergolong tidak aktif melakukan kunjungan ANC sebenarnya sudah mengetahui tentang pentingnya ANC, kapan serta berapa kali dia harus melakukan ANC pada masing-masing trimesternya. Hal ini juga menunjukkan bahwa responden mengerti pentingnya pemeriksaan kehamilan. Pemeriksaan kehamilan yang sesuai dengan standart dan teratur mempunyai manfaat besar bagi ibu hamil sehingga dapat menyiapkan fisik dan mental dengan baik. Sehingga pemeriksaan antenatal dapat digunakan untuk menurunkan angka kematian ibu dan bayi yang masih tinggi di Indonesia.

\section{Pendampingan Kader Dengan Kunjungan ANC}

Berdasarkan tabulasi silang diketahui bahwa pelaksaaan pendampingan kader pada ibu hamil dalam kategori baik dan termasuk dalam kategori kunjungan ANC yang aktif sebanyak 30 responden $(55,6 \%)$. Berdasarkan hasil uji statistik dengan menggunakan uji Mann-Whitney $\mathrm{U}$ didapat $\mathrm{r}_{\text {value }}=0,001(\mathrm{r}<0,05)$ sehingga $\mathrm{H}_{o}$ ditolak berarti disimpulkan ada hubungan Pelaksanaan Pendampingan Kader dengan Kunjungan ANC Ibu Hamil Risti di Puskesmas Jelakombo Kabupaten Jombang.

Menurut Wiryasaputra (2006) sebagai kader (fasilitator) harus mampu mengetahui kebutuhan kliennya, mampu memberikan penjelasan, mampu memberikan saran sesuai dengan kebutuhan kliennya. Seorang motivator harus mampu mempengaruhi prilaku klien sehingga klien berprilaku positif sesuai yang diharapkan. Motivator harus memberikan dukungan kepada klien dan dibangkitkan keyakinannya yang salah selama ini. Kader sebagai mediator mampu memberikan informasi yang diperlukan pihak keluarga mengenai kondisi klien dan kondisi lembaga, agar dapat memberikan pertimbangan yang tepat dalam menentukan tindakan demi kepentingan klien.kader kesehatan sebagai media perantara antara klien dengan petugas kesehatan sehingga terjalin komunikasi yang baik. Mediator akan menjadikan hubungan bersifat netral tidak memaksakan kehendak, tetapi membawa kearah yang positif. Menurut Triatmi, 2016 bahwa perilaku kerja kader terhadap pelaksanaan program GEBRAK memer- 
lukan kerjasama baik dengan kader yang lain, bidan, kepala puskesmas dan masyarakat.

Hal ini sesuai dengan hasil penelitian di Puskesmas Jelakombo bahwa kader yang memfasilitasi dengan baik akan membantu kebutuhan ibu hamil dalam melakukan pemeriksaan ANC, jika kader tidak maksimal dalam memfasilitasi ibu hamil maka ibu hamil yang didampinginya juga tidak tertarik untuk melakukan kunjungan secara teratur. Kader yang aktif memberikan motivasi akan mempengaruhi prilaku ibu hamil menjadi teratur untuk melakukan kunjungan ANC, sedangkan kader yang pasif dalam memotivasi ibu hamil maka ibu hamil yang didampinginya juga tidak termotivasi untuk melakukan kunjungan secara teratur. Ada 2 ibu risti yang pelaksanaan pendampingan kader dilakukan terhadapnya begitu bagi tetapi tidak aktif melakukan kunjungan ANC karena dalam posisi luar kota bersama keluarga sehingga luput dari pantauan kader.

Kader sebagai mediator mampu memberikan informasi yang diperlukan pihak keluarga mengenai kondisi klien dan kondisi lembaga, agar dapat memberikan pertimbangan yang tepat dalam menentukan tindakan demi kepentingan klien. Kader kesehatan sebagai media perantara antara klien dengan petugas kesehatan sehingga terjalin komunikasi yang baik. Mediator akan menjadikan hubungan bersifat netral tidak memaksakan kehendak, tetapi membawa kearah yang positif.

Kader yang aktif sebagai mediator akan mengingatkan ibu hamil agar teratur dalam melakukan kunjungan ANC. Seorang mediator sebagai penengah antara ibu hamil dengan petugas kesehatan sehingga klien tidak merasa dipaksa dalam melakukan ANC. Tugas mediator juga melibatkan keluarga klien agar ikut mendorong ibu hamil melakukan kunjungan ANC secara teratur.

Hasil penelitian menunjukkan bahwa untuk meningkatkan kunjungan ANC ibu hamil resiko tinggi diperlukan pendampingan kader yang memiliki kemampuan aktif sebagai fasilitator, aktif sebagai motivator sehingga ibu hamil mendapatkan dorongan ke arah prilaku yang baik yaitu melakukan kunjungan ANC secara rutin, selain itu diperkukan kemampuan kader lainnya yaitu sebagai mediator yang aktif dan melakukan pendampingan pada saat ibu hamil melakukan kunjungan ANC ke pelayanan kesehatan(USAID (2014)).

Kader kesehatan sangat diperlukan dalam memudahkan kegiatan kesehatan yang ada dimasyarakat.Kader merupakan anggota masyarakat sehingga mudah dalam melaksanakan tugasnya karena mereka berada dekat di tengah-tengah masyarakat sehingga lebih memahami situasi masyarakat tersebut. Kader kesehatan yang aktif di masyarakat akan membawa perubahan perilaku di masyarakat tersebut. Pendamping berperan aktif sebagai agen yang memberikan masukan positif dan direktif berdasarkan pengetahuan dan pengalamannya serta bertukar gagasan dengan pengetahuan dan pengalaman masyarakat yang didampinginya, membangkitkan kesadaran masyarakat, menyampaikan informasi, melakukan konfrontasi, menyelenggarakan pelatihan bagi masyarakat adalah beberapa tugas yang berkaitan fungsi kader sebagai pendamping. Kader yang mendampingi ibu hamil resiko tinggi diharapkan dapat membantu bidan atau tenaga kesehatan memantau ibu hamil resiko tinggi sehingga ibu dapat menjalani proses kehamilan dengan baik dan melahirkan dengan selamat. Kader dan tenaga kesehatan perlu bekerja sama dalam menjalankan tugasnya di masyarakat sehingga dapat mewujudkan masyarakat yang sehat.

\section{KESIMPULAN}

Terdapat hubungan Pelaksanaan Pendampingan Kader dengan Kunjungan ANC Ibu Hamil Risti di Puskesmas Jelakombo Kabupaten Jombang. Kader yang menjalankan tugas dan fungsinya dengan baik sangat efektif dalam meningkatkan kunjungan ibu hamil risti ke nakes. Kader kesehatan merupakan motor atau penggerak masyarakat agar ibu dan keluarganya lebih menyadari pentingya memeriksakan kehammilannya. Adanya perhatian, motivasi dan penadampingan kader akan lebih memudahkan ibu hamil untuk mengakses tenaga kesehatan dan fasilitas pelayanan kesehatan. 


\section{REFERENCES}

Gunawan, G., Fadlyana, E., Rusmil, K., et al. (2016). Hubungan Status Gizi dan Perkembangan Anak Usia 1 - 2 Tahun. Sari Pediatri 13, 142-142. doi: 10.14238/sp13.2.2011.142-

Jombang, D. K. K. (2017). Dinas Kesehatan Kabupaten Jombang.

Liu, L., Oza, S., Hogan, D., Perin, J., Rudan, I., Lawn, J. E., et al. (2015). Global, regional, and national causes of child mortality in 2000-13, with projections to inform post-2015 priorities: an updated systematic analysis. The Lancet 385 430-440. doi: 10.1016/s0140-6736(14)61698-6.

Manuaba, I. B. G. (2005). Buku Ajar Patologi Obstetri, and others (ed.) (Jakarta: PT Yayasan Bina PustakaSarwono Prawirohardjo).

Maryati, H. (2017). Pendidikan kesehatan tentang optimalisasi kader dalam deteksi dini komplikasi hipertensi di desa rejoagung kecamatan ploso kabupaten jombang. Jurnal Pengabdian Masyarakat Kesehatan 3, 12-14.

R, L. (2013). Applying Nursing Process: a step by step guide. J.BLippincott.

Timur, D. K. P. J. (2014). Profil Kesehatan Provinsi Jawa Timur Tahun 2014 . https://dinkes.jatimprov.
go.id/userfile/dokumen/PROFIL\%20KESEHATAN\% 20PROV\%20JATIM\%202014(1).pdf. (Accessed on 17 April 2020).

USAID (2014). Buku Saku Motivator Kesehatan Ibu dan Anak. 1 edn. (Jakarta).

Wiryasaputra, T. S. (2006). Ready to Care: Pendampingan dan Konseling Psikologis (Yogyakarta: Galang Press).

Conflict of Interest Statement: The authors declare that the research was conducted in the absence of any commercial or financial relationships that could be construed as a potential conflict of interest.

Copyright (c) 2020 Rahayu and. This is an open-access article distributed under the terms of the Creative Commons Attribution License (CC BY). The use, distribution or reproduction in other forums is permitted, provided the original author(s) and the copyright owner(s) are credited and that the original publication in this journal is cited, in accordance with accepted academic practice. No use, distribution or reproduction is permitted which does not comply with these terms. 